\title{
Understanding demand for family planning and reproductive health services through the Indian National Health Insurance Scheme in Uttar Pradesh
}

Arupendra Mozumdar

Population Council

Kumudha Aruldas

Population Council

Aparna Jain

Population Council

Laura Reichenbach

Population Council

Robin Keeley

See next page for additional authors

Follow this and additional works at: https://knowledgecommons.popcouncil.org/departments_sbsr-rh

Part of the Demography, Population, and Ecology Commons, Family, Life Course, and Society

Commons, International Public Health Commons, and the Women's Health Commons

How does access to this work benefit you? Let us know!

\section{Recommended Citation}

Mozumdar, Arupendra, Kumudha Aruldas, Aparna Jain, Laura Reichenbach, Robin Keeley, and M.E. Khan. 2016. "Understanding demand for family planning and reproductive health services through the Indian National Health Insurance Scheme in Uttar Pradesh," Policy brief. Washington, DC and New Delhi: Population Council, The Evidence Project. 


\section{Authors}

Arupendra Mozumdar, Kumudha Aruldas, Aparna Jain, Laura Reichenbach, Robin Keeley, and M.E. Khan 



\section{STUDY DESIGN}

A cross-sectional study using both quantitative and qualitative methods was conducted among BPL families in 51 urban slums in three cities of Uttar Pradesh, India: Allahabad, Kanpur, and Lucknow (which had about 1,000, 9,000, and 16,000 RSBY-enrolled families, respectively). The sample size target of 800 was distributed according to the proportion of RSBY-enrolled families in the three cities: 100 in Allahabad, 300 in Kanpur, and 400 in Lucknow. Among the listed RSBY households with eligible women (married and between the ages of $18-35$ years), participants from 810 households were interviewed. In many households, women and men were not both available for the interview, therefore, from 810 households, 726 women and 640 men were interviewed.

Interviews were also conducted with hospital heads and doctors of the RSBY empaneled hospitals, and ration shop owners from the three cities.

\section{USE OF RSBY ENTITLEMENTS FOR FP AND RH}

Among study participants, no women and $0.2 \%$ of men reported that their family used FP services through RSBY since receiving their last RSBY card. For delivery services, only $2 \%$ of RSBY-enrolled women who delivered within the two years prior to the survey reported using RSBY. Interestingly, $22 \%$ of these RSBY-enrolled women delivered in a non-empaneled private clinic or hospital. Only 19\% of women and $30 \%$ of men interviewed knew of FP service coverage and $25 \%$ of women and $33 \%$ of men knew of RH service coverage under RSBY. To better understand RSBY supply and demand side factors that could be contributing to this low awareness and use of RSBY for FP/RH, a graphic depiction of the six pathways of action among the four key stakeholders in the RSBY program (Figure 1) was developed.

This brief focuses on elements in pathways 3 and $4-$ which depict the relationships among RSBY beneficiaries, the insurance company that implements RSBY, and empaneled hospitals that provide RSBY services - that impact demand for RSBY services, specifically FP/RH services. A companion brief examines supply side factors associated with pathways $1,2,4,5$, and 6 , which illustrate the relationships among SACHI, which administers the RSBY program at the state level, the insurance company, and empaneled hospitals.

This study identified several demand side factors of the insurance scheme that hinder knowledge of and access to services, including FP services among enrollees and potential enrollees.

\section{FIGURE 1. PATHWAYS OF ACTION AMONG THE STAKEHOLDERS IN THE RSBY PROGRAM}

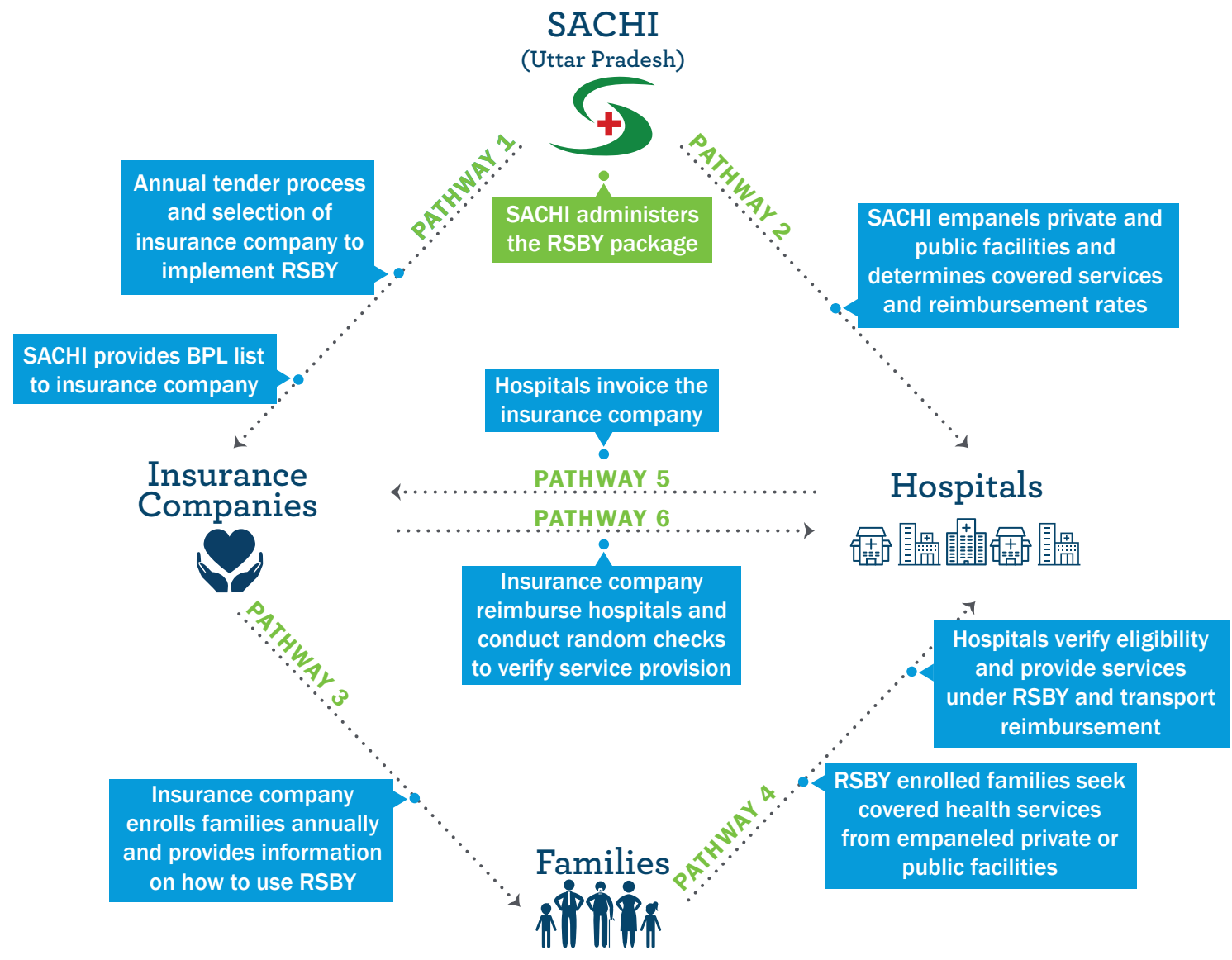




\section{Pathway 3: Insurance Company and RSBY Enrollees}

As shown in Pathway 3, the insurance company is responsible for advertising and enrolling eligible participants into the RSBY program. However, the study found very low levels of knowledge about the program and its benefits among the intended beneficiaries. More than half of women (67\%) and men $(66 \%)$ knew about general treatment under RSBY and less than 40\% knew about FP/RH services from RSBY. About $31 \%$ of women and men did not know of any services covered by RSBY.

\section{SOURCE OF INFORMATION ABOUT}

\section{RSBY}

As shown in Figure 2, the majority of respondents learned of the RSBY program from their neighbors, while local ration shops, where BPL families can buy lower cost groceries, ranked second. Ration shop owners learned about the scheme when the insurance company set up enrolment camps in front of ration shops. Insurance company representatives, though not an insignificant source, were not among the top cited information sources. Importantly, when non-RSBY-enrolled families were asked about their reasons for not enrolling, nearly 94\% reported that they did not know such a scheme existed.

\section{6}

"Everybody in my neighborhood was talking about the enrollment into smart card [RSBY card]. So we went, and got our card made."

-Woman, 30 years, Kanpur

"I came to know about the health insurance scheme from the ration shop owner. We made this card when he told me. The camps [enrollment] were set up twice at his place.... I did not get anything before my enrollment in writing like leaflet or did not see anything about the scheme in poster or television." -Man, 36 years, Lucknow

Health workers, such as Anganwadi workers or those who work for NGOs, were an uncommon source of information about the RSBY program, named by $2.5 \%$ and $0.1 \%$ of women, respectively. Yet these health workers, who often visit BPL families (the RSBY target group) at their homes, could be a valuable source of information about the program, particularly $\mathrm{FP} / \mathrm{RH}$ services.
FIGURE 2. REPORTED SOURCES OF INFORMATION ABOUT RSBY

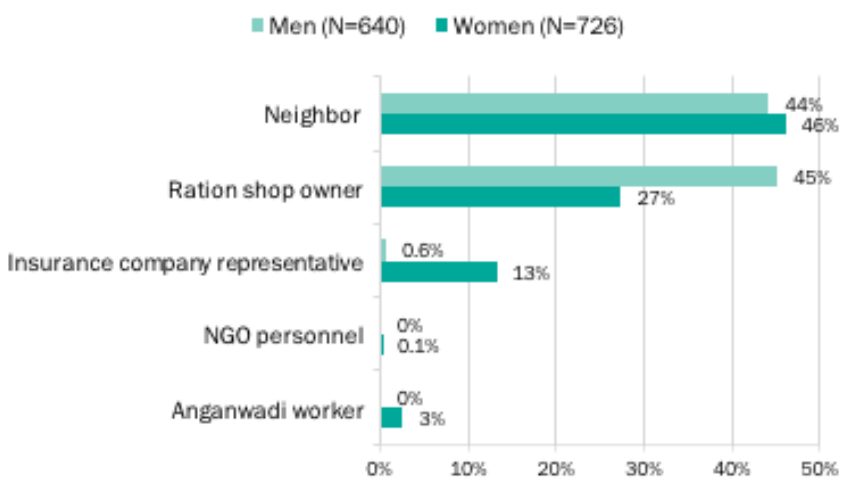

\section{RECOMMENDATIONS}

- Health workers should be given information on the RSBY program to provide when they visit families. Since this would be an added task, some type of remuneration system, possibly through the insurance company, could be established for new RSBY enrollees referred by the workers. The health workers can also inform and remind enrollees about the toll free number for lodging any complaints about the RSBY card.

- Ration shops should be maximized as a channel of information about the RSBY program by giving information on the program to ration shop owners, displaying visual media, and perhaps even using these locations for enrollment campaigns.

- Social networks, such as neighbors, are very important for increased knowledge. Newly enrolled families can be given information on the program to provide to their neighbors.

- Empaneled hospitals can provide space for insurance company representatives to set up an information/enrollment desk, so those coming for services can easily learn about the program and enroll during their visit. Also, private hospitals can include messages on RSBY as part of existing health camps or outreach work, to raise awareness among BPL families of the program and the enrollment process.

\section{REASONS FOR NOT UTILIZING RSBY ENTITLEMENTS}

The most common reason (62\%) reported by women for not using services generally at an RSBY hospital was that they did not know the service they were seeking was covered by RSBY; this was also a common reason (37\%) women gave for not using RSBY delivery services. For men, the most common reason was not feeling the need to go to a private hospital $(42 \%)$ as the same service can be availed from public facilities, followed by not knowing the service they were seeking was covered by RSBY (28\%). 
The study also demonstrated that, given the low literacy rate among intended RSBY beneficiaries, better communications channels are needed to provide information on RSBY to those beneficiaries. Among survey participants, 44\% of women and $32 \%$ of men could neither read nor write, indicating that non-written means of communication are important as a complement to more traditional written communication. Among the mass media channels, television had the best reach with $76 \%$ of women and $38 \%$ of men watching more than once a week. Ownership of mobile phones was also high, with $50 \%$ of women and $84 \%$ of men having a personal mobile phone, and $94 \%$ of women and $95 \%$ of men reporting that they would like to receive messages about RSBY on their phone. However, $70 \%$ of women and $57 \%$ of men preferred those phone communications to be voicemail.

\section{RECOMMENDATIONS}

- SMS and voice messages to mobile phones can be used to increase awareness among BPL families about RSBY and upcoming insurance company enrollment camps. More than $50 \%$ of women and $\mathbf{8 4 \%}$ of men in this study had a personal mobile phone, and of these, all women and men agreed to be contacted later on that phone. Both women and men overwhelmingly preferred messages by voicemail ( $70 \%$ and $57 \%$ ), although $12 \%$ of women and $8 \%$ of men preferred SMS. Both of these methods could be used by insurance companies to raise awareness of RSBY and inform prospective enrollees of when and where they can enroll.

- Existing programs that work to increase health knowledge among target groups that include BPL families could be asked to include messages on RSBY. They could also help develop informational materials appropriate for both literate and illiterate audiences, to expand the reach of informational posters and brochures.

- Special attention is required to create awareness and facilitate utilization of RSBY for FP/RH services. The greatest use of FP/RH services among women was for delivery services. Information boards in delivery wards and recovery areas describing the FP/RH services offered under RSBY could increase utilization of other RH services, including FP.

\section{Pathway 4: Empaneled Hospitals \& RSBY Families}

Some reasons for non-use of RSBY occurred at service delivery points. Due to low levels of knowledge about processes, services, and benefits offered under RSBY, enrolled families often failed to produce their RSBY cards at the time of hospital admission and to complete the appropriate paperwork, leading to out of pocket payments for covered services or denial of services. Many families (59\%) also believed that only in-patient services are covered under RSBY, although the scheme covers select FP day care surgeries.

Additionally, although RSBY provides for reimbursement of travel costs to the empaneled facility for covered services, less than $15 \%$ of men or women knew of the transport reimbursement, the amount of reimbursement, or the requirements to obtain the reimbursement (see Figure 3).

\section{FIGURE 3. KNOWLEDGE OF RSBY-SUPPORTED TRANSPORT REIMBURSEMENT}

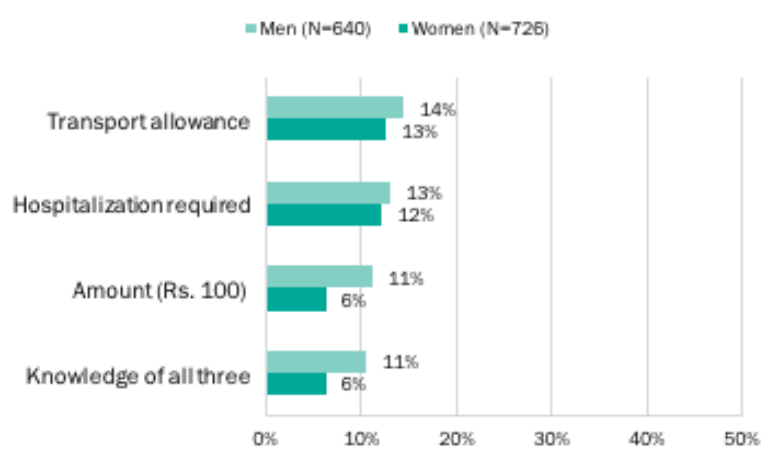

\section{RECOMMENDATION}

Upon enrollment, insurance company representatives should provide RSBY families with easily understandable written and visual instructions to accompany a verbal explanation of covered services and the process for utilizing services in empaneled facilities. Community level meetings hosted by the insurance companies and/or local NGOs could also be held to inform and remind clients of their entitlements and ensure that enrolled families hold empaneled facilities accountable for providing covered benefits and services.

The RSBY scheme has the potential to expand health care access, including to $\mathrm{FP} / \mathrm{RH}$ services, for BPL families. By identifying barriers and potential improvements, this brief is intended to contribute to the increased effectiveness and use of this program.

\section{THE EVIDENCE PROJECT} Population Council Zone 5A, Ground Floor India Habitat Centre, Lodhi Road New Delhi, Delhi 110003

evidenceproject@popcouncil.org

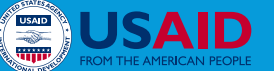
The Evidence Project is made possible by the generous support of the American people through the United States Agency for International Development (USAID) under the terms of cooperative agreement no. AID-OAA-A-13-00087. The contents of this document are the sole responsibility of the Evidence Project and Population Council and do not necessarily reflect the views of USAID or the United States Government. Evidence of evidence-to strengthen and scale up family planning and reproductive health programs to reduce unintended pregnancies worldwide. The Evidence Project is led by the Population Council in partnership with INDEPTH Network, International Planned Parenthood Federation, PATH, Population Reference Bureau, and a University Research Network.

Suggested Citation: Mozumdar, A., K. Aruldas, A. Jain, L. Reichenbach, R. Keeley, and M.E. Khan. 2016. “Understanding demand for family planning and reproductive health services through the Indian National Health Insurance Scheme in Uttar Pradesh," Policy Brief. Washington, D.C. and New Delhi: Population Council, The Evidence Project. 